pp. 1-21, 2001;

http://www.atbp.onaft.edu.ua/

[4] A. Mukolyants, "Energoeffektivnost' ispol'zovaniya ustanovki goryachego vodosnabzheniya na osnove solnechnogo kollektora", CETERIS PARIBUS, no. 2, pp. 8-12, 2015;

[5] Y. K. Todortsev, I. N. Maksimenko, “Ob"yektno-oriyentirovannaya model' sistemy teplosnabzheniya. Informatsionnyye modeli”, Trudy Odesskogo politekhnicheskogo universiteta, no. 2(24), pp. 160-164, 2005;

[6] S. K. Luneva, "Effektivnost' primeneniya teplovykh nasosov", Tekhniko-tekhnologicheskiye problemy servisa, no. 3(33), pp. 59-62, 2015;

[7] Ustroystvo WebHMI. - Dnepropetrovsk: Raspredelennyye informatsionnyye sistemy, 2016. - [Elektronnyy resurs]. URL: http://webhmi.com.ua/ru/ (data obrashcheniya: 17.09.2017).

УДК 681.51

\title{
РАЗРАБОТКА СОВРЕМЕННОГО ЧЕЛОВЕКО- МАШИННОГО ИНТЕРФЕЙСА В АСУТП НА ОСНОВЕ МЕЖДУНАРОДНЫХ СТАНДАРТОВ
}

\author{
А.Ф. Арабаджи ${ }^{1}$, А.А. Стопакевич ${ }^{2}$, А.А. Стопакевич ${ }^{3}$ \\ ${ }^{1,2}$ Одесский национальный политехнический университет, Украина \\ ${ }^{3}$ Одесская национальная академия связи, Украина
}

ORCID: ${ }^{10000-0002-8057-2556, ~}{ }^{2} 0000-0002-8318-685,{ }^{3} 0000-0003-1719-9071$

E-mail: 1alex05godoy@gmail.com, ${ }^{2}$ stopakevich@opu.ua, ${ }^{3}$ stopakevich@ gmail.com

Copyright (C) 2017 by author and the journal "Automation technological and business - processes". This work is licensed under the Creative Commons Attribution International License (CC BY). http://creativecommons.org/licenses/by/4.0/

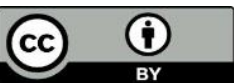

Аннотащия: Показана актуальность разработки промышленных человеко-машинных интерфейсов, поскольку с их неправильной организацией связано $35-58 \%$ ошибок операторов-технологов. Проведена разработка человекомашинного интерфейса для ведения технологического проиесса переработки попутного нефтяного газа с использованием рекомендаций стандарта ANSI/ISA-101.01-2015 и данных опытных исследований. Выбраны критерии эффективности ЧМИ - способность интерфейса минимизировать влияние таких особенностей как степень автоматизаџии, поддержка когнитивной деятельности, поддержка больших объемов данньх, поддержка вторичной деятельности и навигаџии, виртуализации реальности при удобстве использования экранов ЧМИ для решения поставленных задач. Проведен проблемно-ориентированный анализ технологического прочесса и вылелень задачи, которые оператор должен решать с помощью интерфейса. Для выполнения этих задач разработаны экрань человеко-машинного интерфейса, которые соответствует основньлм критериям ситуационной осведомленности.

Abstract: The relevance of the development of industrial human-machine interfaces is shown, since 35-58\% of errors of process operators are associated with their incorrect organization. The development of a HMI for the associated petroleum gas processing technology was carried out using the recommendations of the ANSI/ISA-101.01-2015 standard and pilot studies data. The criteria for the effectiveness of HMI are selected - the ability of the interface to minimize the impact of such design problems as the degree of automation, support for cognitive activity, support for large amounts of data, support for secondary activity and navigation, and virtualization of reality when the HMI screens are used more conveniently for solving the tasks. A problem-oriented analysis of the technological process was carried out and tasks that should be solved with the help of the operator's interface were singled out. To fulfill these tasks, HMI screens have been developed that meet the basic criteria of situational awareness.

Ключевые слова: Человеко-машинный интерфейс, ЧМИ, взрывоопасное производство, переработка газа, ситуационная осведомленность, проблемы проектирования. 
http://www.atbp.onaft.edu.ua/

Keywords: Human-machine interface, HMI, explosive production, gas processing, situational awareness, design problems.

\section{Введение}

Основными факторами, определяющими развитие человеко-машинных интерфейсов (ЧМИ), являются возрастание возможностей для реализации компьютерных интерфейсов и усложнение АСУТП. Оба фактора требуют систематического пересмотра концепции эффективного интерфейса оператора технологического процесса. Несмотря на увеличение возможностей по выдаче большего количества информации, её обработки и отображения, качество реализации интерфейсов в основном падает. В соответствии с комплексными исследованиями производств США, Канады и Европы, проведенными консорциумом ASM, который включает компании Honeywell, Shell, BP и др., источниками ненормального хода технологического процесса во многом являются ошибки операторов-технологов и ошибки организации производства. Процентная доля таких ошибок составляет 35-58\% [1].

Ясно, что проблемы с поломкой оборудования и нарушением хода технологического процесса предотвратить полностью невозможно. А проблемные ситуации на взрывоопасных производствах несут не только экономические потери, но экологический вред и человеческие потери. В то же время, проблемы с качеством реализации ЧМИ и организацией работы оператора-технолога могут быть во многом предотвращены. Выделим 4 типа ошибок при взаимодействии с ЧМИ: пользователь сформулировал неадекватную цель, пользователь некорректно воспринял полученную информацию, пользователь не нашел нужного элемента за требуемое время, пользователь не имеет представление как выполнить определенное действие [2]. Видно, что два типа ошибок больше связаны с представлением данных, а два - с организацией графического интерфейса, качеством подготовки оператора и документации. Таким образом, формирование требований к современным ЧМИ и рекомендаций по их реализации является актуальной задачей.

Целью статьи является исследование принципов реализации современных человеко-машинных интерфейсов в АСУТП с приложением к разработке интерфейса АСУТП установки переработки попутного газа нефтегазовой отрасли и выработка рекомендаций с учетом международных стандартов. В качестве критерия эффективности интерфейса принята его способность минимизировать влияние проблем проектирования и удобство использования экранов ЧМИ.

Анализ последних исследований и публикаций.

Разработка ЧМИ общего назначения регламентируется стандартами серии ISO 9241 «Эргономика человекомашинного взаимодействия». Следование рекомендациям стандарта дает возможность избежать негативного влияния ряда факторов, связанных с физическими и когнитивными особенностями людей, которые работают с графическим интерфейсом. В стандарте также формулируются требования к монитору, устройствам ввода, рабочему месту, документации и т.д. Более подробно использование стандарта рассмотрено в монографии [3]. Однако, этот стандарт, как и ряд других, касающихся темы разработки ЧМИ и сопроводительной документации, такие как ISO 13407, ISO 12119, ISO 9126, разработаны в 1990-х годах и не учитывают последующего опыта и развития техники. Этот недостаток не исправляют принятые за это время в ряде стран отраслевые стандарты, которые хотя и обобщают различные аспекты разработки АСУ для опасных производств (атомные станции, нефтехимия, космонавтика и т.п.), но не обращают должного внимания на проблему разработки ЧМИ, ссылаясь на стандарты ISO, IEC или ISA. Существенным прогрессом в сфере стандартизации процесса разработки промышленных ЧМИ стало появление стандарта ANSI/ISA-101.01-2015. Основные идеи стандарта: отказ от распространенного подхода к построению промышленного ЧМИ на базе схем автоматизации, отказ от избыточной графики и анимации, отображение трендов на основных экранах, отображение данных с возможностью быстрой оценки их соответствия норме.

Наиболее ценные рекомендации, обобщающие опыт эксплуатации более сотни производственных ЧМИ, содержатся в книге [4]. Основные проблемы, которые возникают при проектировании интерфейсов для опасных производств (на примере АЭС) проанализированы в работе [5].

К проблемам автор относит:

- распределение функций между человеком и автоматикой, т.е. определение степени автоматизации;

- поддержку когнитивной деятельности, т.е. представление данных таким образом, чтобы оператор в критической ситуации принял верное и быстрое решение;

- большие объемы данных, т.е. избыточность данных, организацию навигации для поиска требуемых данных и т.П.;

- организацию работы с экранами, переключение экранов, ввода данных и т.п.;

- управления вниманием, т.е. к чему и как привлекать внимание оператора;

- $\quad$ виртуализации реальности, т.е. оператор не чувствует, чем конкретно он управляет, технологические агрегаты превращаются в избыточно абстрактные.

Таким образом, тема разработки ЧМИ важна для АСУТП всех производств, но особенно остро проявляется на взрывоопасных производствах. Ряд рекомендаций имеющихся стандартов являются устаревшими и слишком общими, ряд не актуальны для промышленных интерфейсов, а ряд нарушаются в распространенных решениях систем автоматизации. Следовательно, возникает необходимость в обобщении множества рекомендаций, выделении основных и наиболее значимых. Для этого проведем разработку ЧМИ для одного из ответственных АСУТП, опираясь 
на указанные выше рекомендации.

http://www.atbp.onaft.edu.ua/

Краткая характеристика основных ЧМИ уровня АСУТП.

Характеристика приведена в табл. 1.

Ввиду ограниченности объема статьи, подробное исследование и выработку рекомендаций проведем для ЧМИ ведения технологического процесс. При этом, выберем ТП производства товарного метана (ТМ), пропан-бутана (ПБ) и несертифицированного газа (НГ) из попутных нефтяных газов (ПНГ) на одноколонной газофракционной установке. Технологическая схема ТП состоит из следующих агрегатов: низкотемпературная установка с входным сепаратором, теплообменник газ/газ, холодильник, низкотемпературный сепаратор, ректификационная колонна (РК). Очищенный и осушенный ПНГ, после сжатия в компрессоре до давления 4 МПа поступает в сепаратор, в котором из газа выделяются жидкие компоненты, что позволяет их грубо отделить от метана и этана. Сверху сепаратора газ направляется в теплообменник газ/газ, где охлаждается природным газом. Дальше охлаждение происходит с помощью чиллера, в котором тяжелые углеводороды конденсируются для обеспечения в товарном метане необходимой точки росы для транспортирования в ГТС. Жидкий газ, который сконденсировался в низкотемпературном сепараторе, смешивается с жидким газом, поступившим из входного сепаратора. Полученная смесь после снижения давления подогревается и поступает в РК. Нижний продукт РК - пропан-бутан, верхний несертифицированный («жирный») газ для переработки в ТЭС или котельной. Регламент ТП допускает наличие пропана в верхнем продукте - несертифицированном газе, поскольку полное разделение энергетически неэффективно (требуется охлаждение флегмы до низких температур с дорогими хладагентами). Процесс и система управления им описаны в работах [6,7].

Таблица 1 - Краткая характеристика основных ЧМИ уровня АСУТП

\begin{tabular}{|c|c|c|c|c|}
\hline № & ЧМИ & Назначение & Управляется & Должен обеспечить \\
\hline 1 & $\begin{array}{l}\text { Ведения } \\
\text { ТП }\end{array}$ & $\begin{array}{l}\text { постоянный } \\
\text { контроль хода ТП }\end{array}$ & $\begin{array}{l}\text { оператором- } \\
\text { технологом }\end{array}$ & $\begin{array}{l}\text { При нарушении хода ТП - выполнить } \\
\text { перенастройку режимных параметров ТП, а при } \\
\text { отказе оборудования - принять решение о останове }\end{array}$ \\
\hline 2 & $\begin{array}{l}\text { Монито- } \\
\text { ринга } \\
\text { АСУТП }\end{array}$ & $\begin{array}{l}\text { постоянный } \\
\text { контроль } \\
\text { функциониро-вания } \\
\text { АСУТП }\end{array}$ & $\begin{array}{l}\text { инженером по } \\
\text { автоматизации }\end{array}$ & $\begin{array}{l}\text { Контроль кабельной системы, выявлять характер и } \\
\text { локализацию неисправностей, проводить } \\
\text { дистанционную настройку интеллектуальных } \\
\text { датчиков и регуляторов. }\end{array}$ \\
\hline 3 & ПАЗ & $\begin{array}{l}\text { мониторинг и } \\
\text { локализация } \\
\text { аварийной ситуации }\end{array}$ & $\begin{array}{l}\text { инженером по } \\
\text { охране труда }\end{array}$ & $\begin{array}{l}\text { Отображение причины принятого решения о } \\
\text { локализации аварийной ситуации и/или останове } \\
\text { ТП, сигнализацию останова ТП. }\end{array}$ \\
\hline 4 & $\begin{array}{l}\text { Автома- } \\
\text { тического } \\
\text { пуска и } \\
\text { останова } \\
\end{array}$ & пуск и останов ТП & $\begin{array}{l}\text { оператором- } \\
\text { технологом }\end{array}$ & $\begin{array}{l}\text { Контроль при пуске и останове за соответствием } \\
\text { процесса регламентным требованиям по времени, } \\
\text { энергетическим затратам и давать возможность } \\
\text { влиять на ход процесса в случае необходимости }\end{array}$ \\
\hline 5 & $\begin{array}{l}\text { Обобщен- } \\
\text { ного } \\
\text { монито- } \\
\text { ринга }\end{array}$ & $\begin{array}{l}\text { мониторинг } \\
\text { параметров ТП на } \\
\text { мобильных } \\
\text { устройствах }\end{array}$ & $\begin{array}{l}\text { руководящим } \\
\text { персоналом }\end{array}$ & Контроль основных параметров ТП по запросу \\
\hline 6 & $\begin{array}{l}\text { Компакт- } \\
\text { ных } \\
\text { сенсорных } \\
\text { панелей } \\
\end{array}$ & $\begin{array}{l}\text { индикация и ввод } \\
\text { ряда показаний }\end{array}$ & $\begin{array}{l}\text { оператором- } \\
\text { технологом и } \\
\text { инженером по } \\
\text { автоматизации } \\
\end{array}$ & $\begin{array}{l}\text { Индикацию определенных показаний и настройку } \\
\text { по месту работы датчиков и/или оборудования. }\end{array}$ \\
\hline 7 & $\begin{array}{l}\text { Кибербез- } \\
\text { опасности }\end{array}$ & $\begin{array}{l}\text { мониторинг } \\
\text { кибербезопасности }\end{array}$ & $\begin{array}{l}\text { инженером по } \\
\text { безопасности. }\end{array}$ & $\begin{array}{l}\text { Контроль доступа, защиту от } \\
\text { несанкционированных соединений, контроль } \\
\text { подключенного оборудования. }\end{array}$ \\
\hline
\end{tabular}

Определение принципов разработки ЧМИ ведения ТП.

Определение принципов проведем исходя из анализа основных проблем проектирования интерфейсов [5] применительно к выбранному ТП.

Проблема степени автоматизации. Технологические процессы в нефтегазовой отрасли относятся к классу взрывоопасных. Используемые системы управления несовершенны и не способны эффективно справляться со всеми возможными возмущениями. Статика и динамика ТП не моделируются с высокой точностью. Датчики состава достаточно инерционны. Переходные процессы в ТП могут проходить часами. В таких условиях возможность вмешательства человека в процесс необходима, поскольку разработка полностью интеллектуальной системы управления для таких ТП пока неразрешима. За оператором должны оставаться следующие возможности вмешательства в ход процесса: изменение режима работы ТП (заданий регуляторам) и ручное управление ТП при отключении регуляторов.

Проблема поддержки когнитивной деятельности. Функциональность элементов интерфейса для оператора 
должна быть легко определяемая. Для этого используются такие средства как цвет, форма и положение на экране. Наиболее быстрым для различения фактором интерфейса является цвет. ISA 101 рекомендует использовать в качестве фона интерфейса светло-серый цвет. Этот цвет минимизирует блики и отражения на экране и оптимален для сравнения с красным, за которым закрепляются аварийные ситуации. За желтым цветом закрепляются предаварийные ситуации. Выбранное значение выбранных цветов приведены в табл. 2.

\section{Таблица 2 - Цветовая карта ЧМИ}

\begin{tabular}{|c|c|c|c|}
\hline Цвет & Значение & Цвет & Значение \\
\hline Черный & Предел параметра & Аквамарин & Допустимая зона изменения параметра \\
\hline $\begin{array}{l}\text { Темно- } \\
\text { серый }\end{array}$ & $\begin{array}{c}\text { Подпись, рамка для } \\
\text { отображения }\end{array}$ & \multirow{2}{*}{ Белый } & \multirow{2}{*}{$\begin{array}{c}\text { Активный элемент (кнопка, текстовое } \\
\text { поле и т.п.) }\end{array}$} \\
\hline $\begin{array}{l}\text { Светло- } \\
\text { серый }\end{array}$ & Фон, неактивный элемент & & \\
\hline Синий & $\begin{array}{c}\text { Текущее и прошлые (на } \\
\text { тренде) значения } \\
\text { параметра, шкала } \\
\text { значений параметра, } \\
\text { нормальное состояние } \\
\text { параметра (при } \\
\text { сигнализации) }\end{array}$ & Желтый & Предупредительная сигнализация \\
\hline $\begin{array}{l}\text { Светло- } \\
\text { синий }\end{array}$ & $\begin{array}{c}\text { Желаемое значение } \\
\text { параметра (заданное либо } \\
\text { регламентное) }\end{array}$ & Красный & Аварийная сигнализация \\
\hline
\end{tabular}

Элементы интерфейса и значение изменения их формы приведены в табл. 3.

Таблица 3 - Элементы ЧМИ

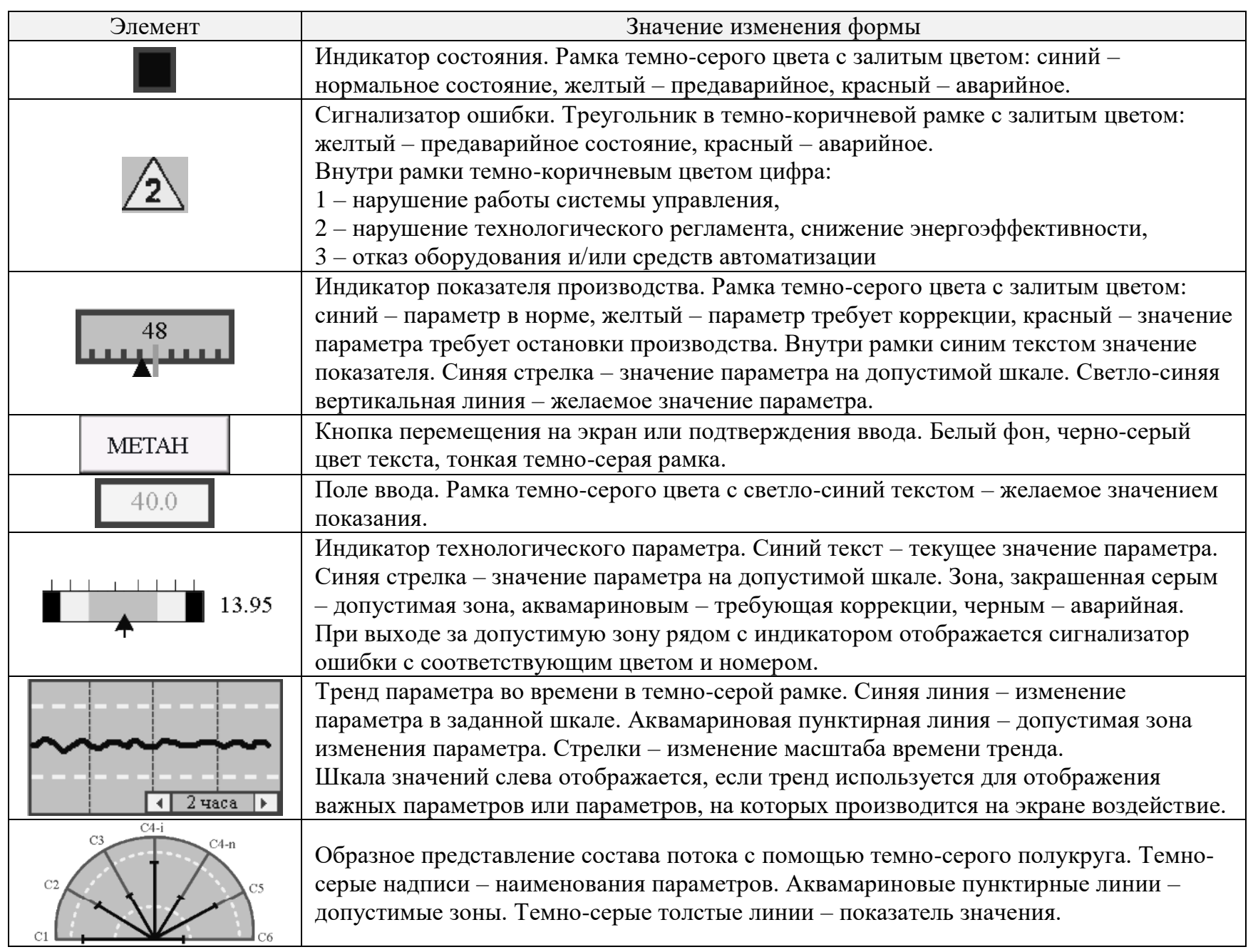


http://www.atbp.onaft.edu.ua/

Положение на экране элементов интерфейсов определяется по зонам для упрощения локализации. Экраны разбиваются на зоны с помощью толстых серых пунктирных линий. Для упрощения определения связей между элементами контура регулирования используется тонкая точечная линия.

Проблема больших объемов данных. Известно, что возможности человеческой памяти ограничены. Поэтому количество переменных, необходимых для принятия решения оператором, в эффективном ЧМИ не должно превышать число Миллера $(7 \pm 2)$. Для достижения этих целей используется три подхода: разбиение информации на экраны, функциональная иерархическая организация экранов, динамическая перестройка экранов.

Разбиение информации на экраны должно основываться на проблемно-ориентированном принципе. Каждый экран должен быть предназначен для решения одной или более задач. Информации на экране должно быть достаточно для решения поставленной задачи, но сам экран не должен по возможности быть перегруженным информацией и избыточно сложным. Для снижения сложности используется разделение экрана на логические зоны и представление информации с помощью наиболее подходящих элементов.

ISA 101 выделяет четыре уровня иерархии экранов.

Экран первого уровня (L1, Overview) должен позволять оценить эффективность проведения ТП путем оценки ключевых показателей, позволяющих оценить следующие факторы: объем производства, качество продукции, энергетическая эффективность, состояние системы управления, основных технологических агрегатов, безопасность (информация о наличии аварийных и предаварийных ситуаций). Несколько ключевых показателей, которые могут быть использованы для прогнозирования хода ТП, должны отображаться с помощью трендов.

Экран второго уровня (L2, Primary) предназначен для формирования и проверки ментальной модели состояния технологического процесса. Такое понимание дает информация о текущем состоянии материального и энергетического баланса, заданиях и качестве работы системы регулирования, ключевых трендах, позволяющий оценить поддержание технологического регламента. Этот экран должен быть основным для оператора и обычно не должен содержать схему автоматизации.

Экран третьего уровня (L3, Detail) предназначен для подробной оценки хода технологического процесса и коррекции его хода. Это уровень обычно привязывается к схеме автоматизации (но не повторяет её детально), отображает все параметры выбранных технологических агрегатов и позволяет диагностировать и перенастраивать систему управления.

Экран четвертого уровня (L4, Diagnostics) предназначен для детализированного отображения состояния технологических агрегатов, компонентов, средств автоматизации.

Сведем результаты проблемно-ориентированного анализа в табл. 4.

Таблица 4 - Содержимое экранов ЧМИ и решаемые ими задачи

\begin{tabular}{|c|c|c|c|c|}
\hline № & Экран & Зона & Содержимое & Решаемые задачи \\
\hline \multirow{4}{*}{ L1 } & \multirow{4}{*}{$\begin{array}{l}\text { Обзор- } \\
\text { ный }\end{array}$} & $\begin{array}{l}\text { Основные } \\
\text { показатели } \\
\text { производства }\end{array}$ & $\begin{array}{l}\text { Объем произведенной продукции за час и } \\
\text { смену, общая энергоэффективность }\end{array}$ & \multirow{4}{*}{$\begin{array}{l}\text { 1. Оценить эффективность } \\
\text { проведения ТП } \\
\text { 2. Оценить соответствие } \\
\text { основных параметров } \\
\text { регламенту } \\
\text { 3. Оценить и прогнозировать } \\
\text { динамику производства }\end{array}$} \\
\hline & & $\begin{array}{l}\text { Сигнализация } \\
\text { параметров ТП }\end{array}$ & $\begin{array}{l}\text { Сигнализация состояния основных } \\
\text { параметров ТП }\end{array}$ & \\
\hline & & $\begin{array}{l}\text { Состояние } \\
\text { регуляторов }\end{array}$ & Сигнализация состояния регуляторов & \\
\hline & & Тренды & $\begin{array}{l}\text { Объем произведенной продукции, } \\
\text { концентрация метана }\end{array}$ & \\
\hline \multirow{4}{*}{ L2 } & \multirow{4}{*}{$\begin{array}{l}\text { Произ- } \\
\text { водство } \\
\text { ТМ }\end{array}$} & $\begin{array}{l}\text { Параметры } \\
\text { входящего ПНГ }\end{array}$ & $\begin{array}{l}\text { Температура, давление, расход и состав } \\
\text { ПНГ }\end{array}$ & \multirow{4}{*}{$\begin{array}{l}\text { 1. Оценить причины } \\
\text { изменения состава ТМ } \\
\text { 2. Оценить качество работы } \\
\text { системы управления } \\
\text { охлаждением в чиллере } \\
\text { 3. Установить задание на } \\
\text { температуру охлаждения в } \\
\text { чиллере }\end{array}$} \\
\hline & & Параметры ТМ & $\begin{array}{l}\text { Температура, давление, расход и состав } \\
\text { ТМ }\end{array}$ & \\
\hline & & Процесс сепарации & $\begin{array}{l}\text { Температура сепарации с возможностью } \\
\text { установить задание, энергоэффективность } \\
\text { сепарации, расход хладагента в чиллер }\end{array}$ & \\
\hline & & Тренды & $\begin{array}{l}\text { Объем произведенного товарного метана, } \\
\text { концентрация метана }\end{array}$ & \\
\hline \multirow{4}{*}{$\mathrm{L} 2$} & \multirow{4}{*}{$\begin{array}{l}\text { Произ- } \\
\text { водство } \\
\text { пропан- } \\
\text { бутана и } \\
\text { НГ }\end{array}$} & Питание РК & $\begin{array}{l}\text { Температура, давление, расход и состав } \\
\text { смеси }\end{array}$ & \multirow{4}{*}{$\begin{array}{l}\text { 1. Оценить причины } \\
\text { изменения состава НГ и ПБ и } \\
\text { спрогнозировать их динамику } \\
\text { 2. Оценить и спрогнозировать } \\
\text { качество работы системы } \\
\text { управления РК в целом } \\
\text { 3. Принять решение об } \\
\text { изменении задания системе } \\
\text { управления РК }\end{array}$} \\
\hline & & $\begin{array}{l}\text { Профиль и система } \\
\text { управления РК }\end{array}$ & $\begin{array}{l}\text { Значения переменных, поддерживаемых } \\
\text { регуляторами РК. Температурный } \\
\text { профиль РК. }\end{array}$ & \\
\hline & & Произведен-ный НГ & Объем, температура, состав НГ & \\
\hline & & Произведенный ПБ & Объем, температура, состав ПБ & \\
\hline
\end{tabular}



http://www.atbp.onaft.edu.ua/

\begin{tabular}{|c|c|c|c|c|}
\hline \multirow{3}{*}{ L2 } & \multirow{3}{*}{$\begin{array}{l}\text { Ректи- } \\
\text { фи- } \\
\text { кацион- } \\
\text { ная } \\
\text { колонна }\end{array}$} & Давление верха РК & \multirow{3}{*}{$\begin{array}{l}\text { Параметры соответствующей каскадной } \\
\text { системы с возможностью установить } \\
\text { задание, энергоэффективность }\end{array}$} & \multirow{3}{*}{$\begin{array}{l}\text { 1. Оценить качество работы } \\
\text { систем управления } \\
\text { параметрами РК } \\
\text { 2. Установить задание на } \\
\text { регуляторы РК }\end{array}$} \\
\hline & & Пропан в НГ & & \\
\hline & & Уровень в ребойлере & & \\
\hline L3 & $\begin{array}{l}\text { Система } \\
\text { управле- } \\
\text { ния } \\
\text { произ- } \\
\text { вод- } \\
\text { ством } \\
\text { ТМ () }\end{array}$ & - & $\begin{array}{l}\text { Мнемосхема участка производства ТМ, } \\
\text { параметры основных потоков, уровни в } \\
\text { сепараторах, регулятор температуры } \\
\text { сепарации }\end{array}$ & \multirow{2}{*}{$\begin{array}{l}\text { 1. Изменить задание, } \\
\text { настройки регуляторов, } \\
\text { включить и отключить } \\
\text { регуляторы } \\
\text { 2. Ручное управление } \\
\text { регулирующими органами } \\
\text { (при отключении } \\
\text { регуляторов) }\end{array}$} \\
\hline L3 & $\begin{array}{l}\text { Система } \\
\text { управле- } \\
\text { ния } \\
\text { произ- } \\
\text { вод- } \\
\text { ством } \\
\text { НГ и ПБ }\end{array}$ & - & $\begin{array}{l}\text { Мнемосхема участка производства НГ и } \\
\text { ПБ, параметры основных потоков, уровни } \\
\text { в конденсаторе и ребойлере, регуляторы } \\
\text { параметров РК }\end{array}$ & \\
\hline L4 & $\begin{array}{l}\text { Диаг- } \\
\text { ностика } \\
\text { состо- } \\
\text { яния } \\
\text { обору- } \\
\text { дования }\end{array}$ & - & $\begin{array}{l}\text { Мнемосхема технологического процесса с } \\
\text { индикацией состояния всех датчиков и } \\
\text { ИМ по схеме ПАЗ 3оо } 2\end{array}$ & $\begin{array}{l}\text { 1. Определить идентификатор } \\
\text { отказавшего средства } \\
\text { автоматизации и место его } \\
\text { установки }\end{array}$ \\
\hline
\end{tabular}

Динамическая перестройка экранов в рассмотренном случае должна происходить при смене режима работы системы регулирования. Управление системой регулирования доступно из экранов третьего уровня. Состояние регулятора, работающего в автоматическом режиме, и связанный с ними контур отображается на экране как показано на рис. 1а. Состояние отключенного регулятора и связанный с ними контур отображается на экране как показано на рис. 1б. Рядом с соответствующим исполнительным механизмом (ИМ) появляется поле ввода и кнопка ввод, которая позволяет задавать значение управляющего воздействия вручную. Для изменения параметров регулятора нужно на него щелкнуть чтобы появилось всплывающее диалоговое окно, внешний вид которого показан на рис. 1в.

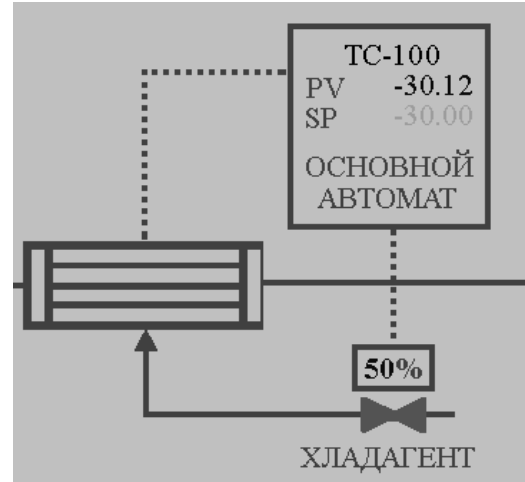

a)

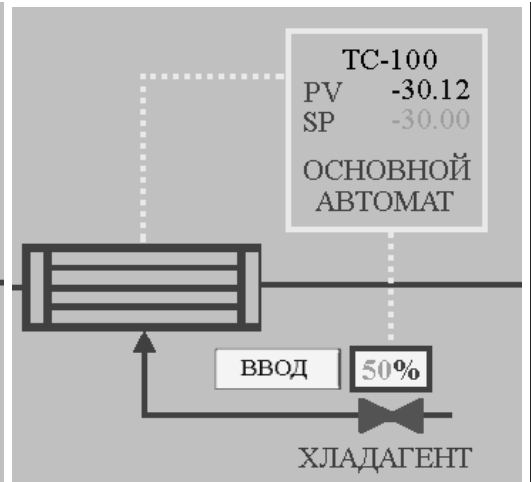

б)

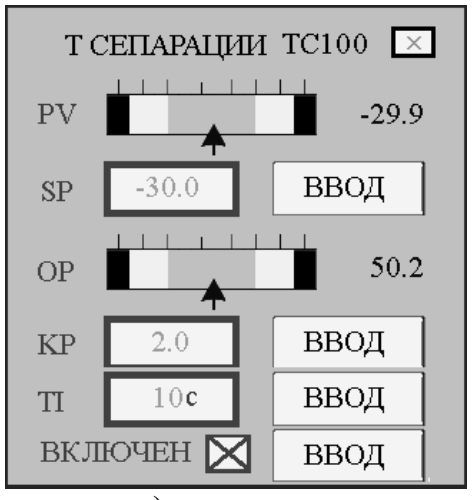

B)

Рис. 1 - Представление системы регулирования

Проблема вторичной деятельности и навигации. Под вторичной деятельностью понимаются принятые процедуры взаимодействия пользователя с графическим интерфейсом. Работа с экраном должна проводиться в удобном и привычном для пользователя ПК формате, при чем современные интерфейсы должны поддерживать управление как мышью, так и с помощью сенсорного экрана. Элементы на экране должны разделяться на активные, т.е. на которые можно воздействовать, и пассивные. Для этого активные элементы (кнопки, поля ввода, флажки) обозначим белым цветом в темно-серой рамке. Текст, который можно ввести, обозначим светло-синим цветом. Все операции оператора должны подтверждаться, например, после ввода значения задания в текстовом поле оператор должен нажать на кнопку «ВВОД».

Проблема навигащии в рассмотренной задаче остро не стоит, поскольку количество экранов равняется 7 , следовательно, их можно физически разместить на отдельных мониторах в помещении оператора. Навигацию организуем с помощью обычных кнопок, выстроенных в порядке возрастания уровня экрана. Для удобства логически 
разделим кнопки перехода на три зоны для перехода на экраны 1 уровня, 2 уровня, 3 и 4 уровней. Для определения текущего экрана кнопка перехода на него закрашивается светло-серым цветом.

Проблема управления вниманием. Внимание оператора должно намеренно привлекаться только к ситуациям, которые имеют предаварийный или аварийный характер. В остальных случаях внимание должно быть максимально свободным.

Для того чтобы не отвлекать внимание оператора используются следующие меры: фон экрана делается светлосерым, оборудование отображается двумерным изображением без теней в низком контрасте с фоном, трубопроводы отображаются темно-серыми или черными линиями, анимация не используется, единицы измерения не выделяются или не показываются.

Для убыстрения фокусировки внимания на требуемых данных используются следующие меры: экран логически разбивается на зоны, параметры для отображения на экране выбираются и отображаются с помощью разных элементов (индикаторов, трендов, образных диаграмм) в зависимости от задачи экрана, значения (но не единицы измерения) параметров выделяются темно-синим цветом, для группировки нескольких параметров потоков они отображаются в одном прямоугольнике.

Для привлечения внимания используется сигнализатор ошибки с соответствующим цветом и номером. Все ошибки выводятся на обзорном экране, на остальных экранах выводятся ошибки, которые логически связаны с их задачами. Для того чтобы определить на какой экран оператору следует перейти для определения подробностей ошибки рядом с кнопкой перехода на экран отображается индикатор ошибки, равно как и рядом с параметром на экране, который к нему относится.

Проблема виртуализации реальности частично решается отображением динамики параметров на каждом экране. Таким образом, процесс воспринимается более «живыми», чем при наблюдении за изменением чисел или показаний стрелочных приборов. Конечно, это не решает поставленную проблему полностью, поэтому задача разработки интерфейса оператора взрывоопасного ТП должна сочетаться с разработкой тренажера. Использование тренажера помогает поддерживать навык решения различных возникающих проблем в ходе технологического процесса, восстанавливает в памяти возможное поведение объекта.

Внешний вид экранов ЧМИ для ТП переработки ПНГ.

Графический интерфейс ЧМИ состоит из 7 экранов, содержимое которых описано в таблице 3. Внешний вид наиболее представительных экранов представлен на рис.2. На рис. 2а показана ситуация снижения энергоэффективности из-за превышения температуры поступающего ПНГ. В данном случае проблема связана с ТП выделения ПНГ. Также один из датчиков отказал, о чем подробнее можно узнать на соответствующем экране.

На рис. $2 б$ показана ситуация снижения концентрации товарного метана. Она может быть связана с падением температуры сепарации ПНГ, которая видна на тренде. На рис. 2в показана ситуация превышения уровня в конденсаторе РК. Подробности ситуации доступны на экране третьего уровня. Ситуация может быть временной, поскольку данный регулятор является ведомым в каскадной системе. На рис. 2 г показана нормальная работа участка сепарации ПНГ. На рис. 2д. показана ситуация ручного управления расходом пара в ребойлер с выключенным регулятором температуры низа. На рис. 2е. показана предаварийная ситуация отказа одного из датчиков температуры и аварийная ситуация с подачей вентиля подач хладагента в чиллер. Оператор должен принять решение о том, возможно ли продолжать процесс или необходимо включать процедуру аварийного завершения.

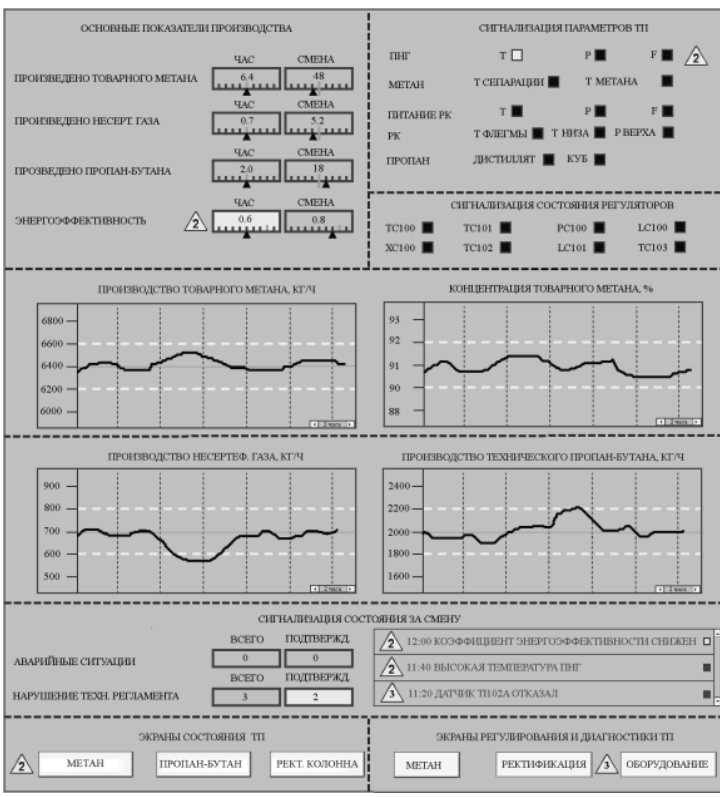

$a$

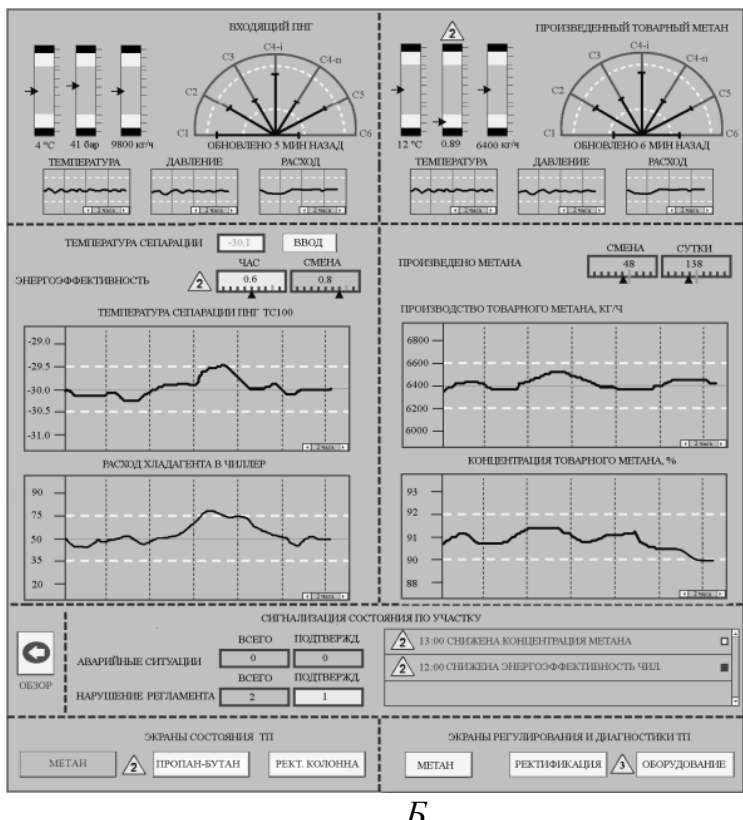

S 


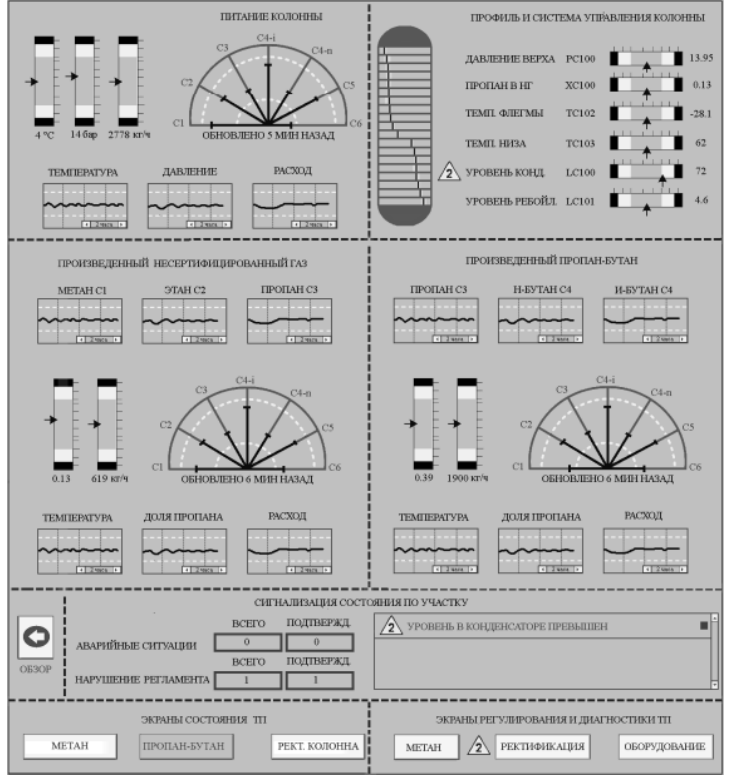

8

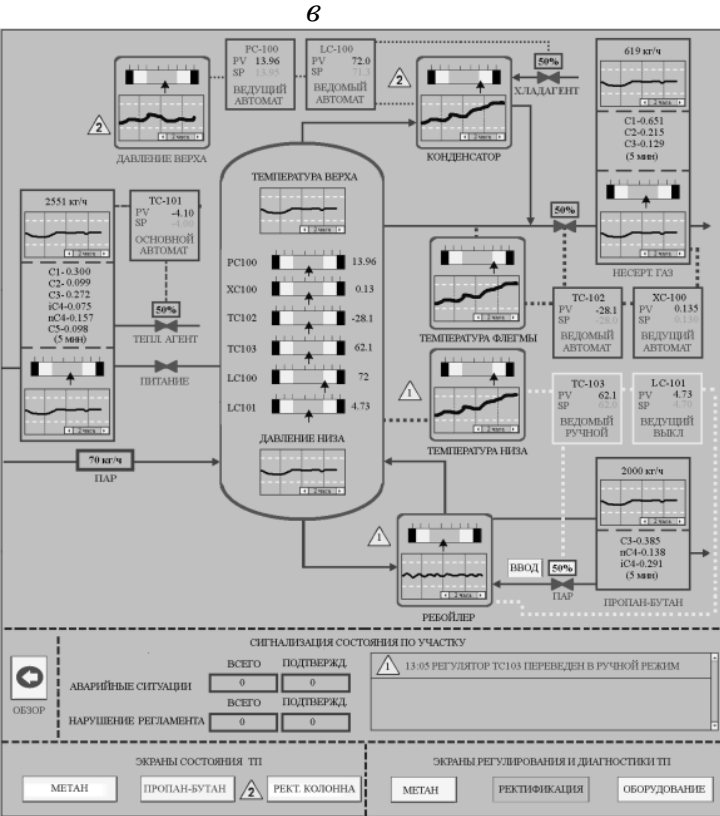

$\partial$
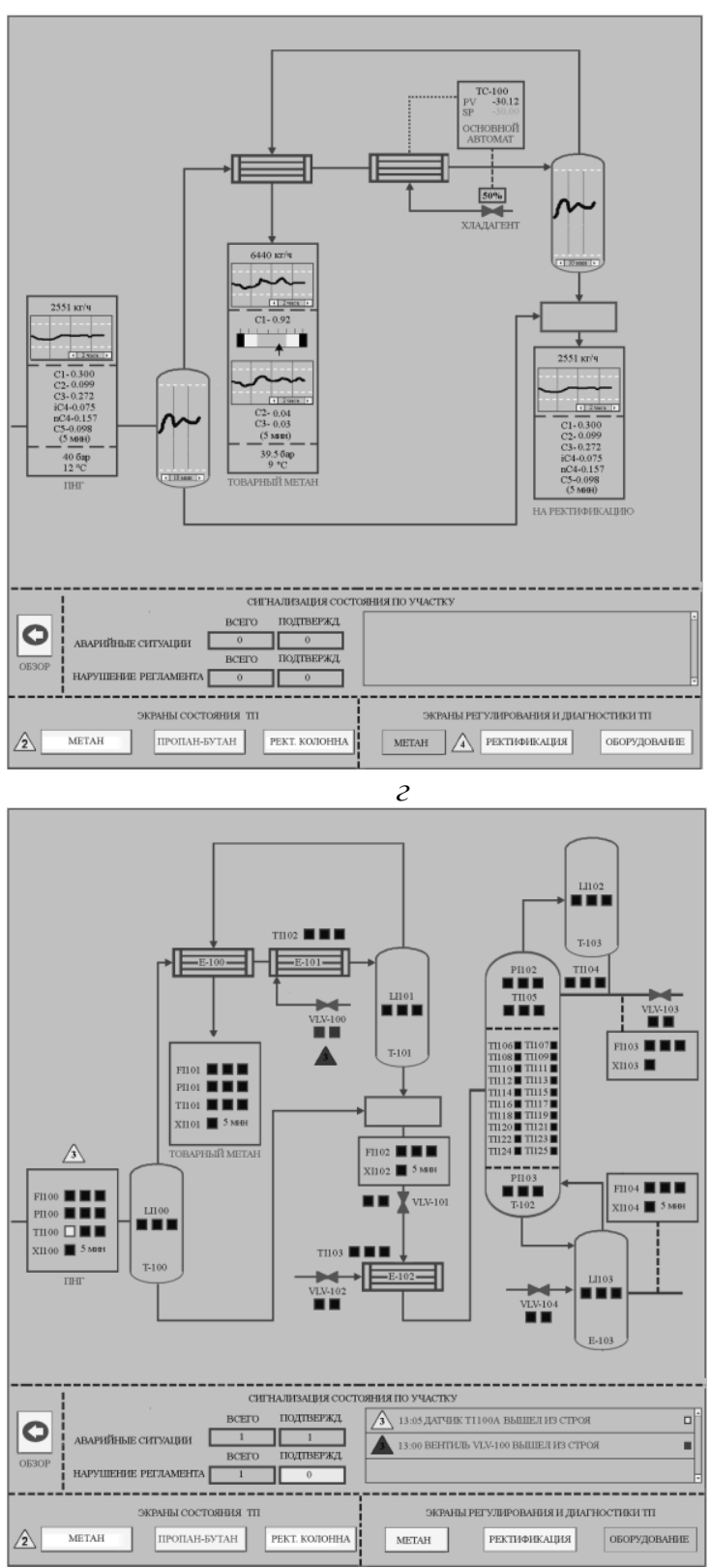

$e$

Рис. 2 - Внешний вид основных экранов ЧМИ

Оценка полученных результатов.

Наиболее общий и подходящий критерий для оценки интерфейса ведения процесса - ситуационная осведомленность (SA, Situational Awareness), от которой зависит правильность принятия решений. В книге [8] проведено подробное исследование понятия ситуационной осведомленности. Рационально рассматривать три уровня ситуационной осведомленности: восприятие, понимание и прогнозирование ситуации.

Для того, чтобы обеспечить ситуационную осведомленность, автор предлагает использовать ряд принципов. Оценим разработанные экраны на соответствие 8 основным принципам.

Таблица 5 - Критерии выполнения принципов ситуационной осведомленности на экранах ЧМИ

\begin{tabular}{|c|l|ll|}
\hline № & \multicolumn{1}{|c|}{ Формулировка принципа } & \multicolumn{3}{|c|}{ Критерии выполнения принципов на экранах ЧМИ рис. 3} \\
\hline 1 & \multicolumn{1}{|c|}{2} & \multicolumn{1}{|c|}{3} \\
\hline 1 & $\begin{array}{l}\text { Организация информации в } \\
\text { соответствии с целями } \\
\text { пользователя }\end{array}$ & $\begin{array}{l}\text { Все экраны построены исходя из анализа задач, которые должен } \\
\text { выполнять оператор }\end{array}$ \\
\hline
\end{tabular}




\begin{tabular}{|c|c|c|}
\hline 1 & 2 & 3 \\
\hline 2 & $\begin{array}{l}\text { Представление информации для } \\
\text { понимания ситуации }\end{array}$ & $\begin{array}{l}\text { Вся основная информация отображается с указанием допустимых зон, } \\
\text { ряд параметров отображается с помощью трендов, а в случае ошибки } \\
\text { сигнализатор появляется у конкретных элементов, с которыми ошибка } \\
\text { связана. Следовательно, оператору не нужно выполнять операции } \\
\text { сравнения с данными из памяти, наличие ошибки определяет система }\end{array}$ \\
\hline 3 & $\begin{array}{l}\text { Представление информации для } \\
\text { прогнозирования ситуации }\end{array}$ & $\begin{array}{l}\text { Наличие трендов позволяет экстраполировать поведение } \\
\text { технологического процесса. Прогнозирование поведения ТП возможно } \\
\text { при наличии точной модели процесса и системы управления, однако для } \\
\text { рассмотренного процесса получить точную модель на текущий момент } \\
\text { не возможно, поэтому реализация прогнозирования не целесообразна }\end{array}$ \\
\hline 4 & $\begin{array}{l}\text { Предоставлять информацию об } \\
\text { общем состоянии процесса }\end{array}$ & $\begin{array}{l}\text { Реализован обзорный экран, который дает такую информацию. Именно } \\
\text { этот экран является отправной точкой для выбора наиболее } \\
\text { приоритетной из возникших задач. }\end{array}$ \\
\hline 5 & $\begin{array}{l}\text { дать компромисс между } \\
\text { рованием целей и } \\
\text { авлением данных }\end{array}$ & $\begin{array}{l}\text { Иерархия уровней экранов позволяет отобразить как состояние данных, } \\
\text { так и их реальные значения. }\end{array}$ \\
\hline 6 & $\begin{array}{l}\text { Представлять } \\
\text { показания сигналов на схеме }\end{array}$ & $\begin{array}{l}\text { Большинство параметров отображаются с указанием предаварийной } \\
\text { зоны, а ряд ключевых также указывают и аварийную зону }\end{array}$ \\
\hline 7 & $\begin{array}{l}\text { Использовать разные модальности } \\
\text { людей в интерфейсе }\end{array}$ & $\begin{array}{l}\text { Может быть выполнен при использовании различных звуковых сигналов } \\
\text { для различных производственных ситуаций }\end{array}$ \\
\hline 8 & $\begin{array}{l}\text { Фильтровать } \\
\text { осторожностью }\end{array}$ & $\begin{array}{l}\text { Пользователю предоставляется вся необходимая для выполнения задачи } \\
\text { информация, однако в зависимости от её характера и приоритета } \\
\text { используются разные способы представления }\end{array}$ \\
\hline
\end{tabular}

Таким образом, разработанный ЧМИ удовлетворяет основным принципам разработки интерфейсов и обеспечивается ситуационную осведомленность, что говорит о его высоком качестве.

Выводы.

Проанализировано текущее положение в области стандартизации ЧМИ АСУТП. Показано, что исследование применимости известных рекомендаций и адекватности традиционных подходов в этой области является актуальной задачей, поскольку человеческий фактор составляет значительный процент аварийных ситуаций. Среди известных стандартов в области промышленных ЧМИ наиболее заслуживающим внимание является стандарт ISA 101. Также заслуживают внимания рекомендации, данные в монографии [8].

Проведена разработка графических экранов для взрывоопасного нефтегазового ТП с использованием проблемно ориентированного подхода. Принципы, положенные в процедуру разработки позволяют минимизировать влияние основных проблем промышленных ЧМИ: степени автоматизации, поддержки когнитивной деятельности, больших объемов данных, вторичной деятельности и навигации, управления вниманием, виртуализации реальности.

Дальнейшим направлением исследования является выделение принципов разработки остальных ЧМИ, из перечисленных в табл.1. Результаты исследования рекомендуется использовать при разработке ЧМИ непрерывных промышленных технологических процессов.

\section{Литература}

[1] Abnormal situation management - effective automation to improve operator performance [Text],- U.S.A., Philadelphia: Honeywell Inc, 2007.

[2] Shneiderman B. Designing the user interface: strategies for effective human-computer interaction [Text] / B. Shneiderman, C. Plaisant, M. Cohen, S. Jacobs, N. Elmqvist, N. Diakopoulos.- Hoboken: Pearson, 2016.

[3] Сердюк С. Ергономічні питання проектування людино-машинних систем [Текст] / С. Сердюк.- 3.: 3НТУ, 2014.

[4] Hollifield B. The high performance HMI handbook. [Text] / B. Hollifield, D. Oliver, I. Nimmo, E. Habibi.- USA, Kalamazoo: Digital Books, 2008.

[5] Анохин А. Проблемы организации человеко-машинного интерфейса АСУ ТП АЭС [Текст] //Доклады БГУИР.2015.- T.88, №2. - C. 104-108.

[6] Stopakevych A. Development of computer-integrated systems for the automation of technological process of associated gas processing [Text] / A. Stopakevych, O. Stopakevych, A. Tigariev // Eastern-European Journal of Enterprise Technologies.- 2017.- V1.3.- P. 4-12.

[7] Арабаджи А. Ф. Синтез двухуровневой системы управления ректификационной колонной в технологическом процессе переработки попутных нефтяных газов [Текст] / А.Ф. Арабаджи, А. А. Стопакевич, А. А. Стопакевич//Автоматизация технологических и бизнес-процессов.- 2017 .- Т. 9, №.2.- С. 11-17.

[8] Endsley M. Designing for situation awareness: an approach for user-centered design [Text]/ M. Endsley.- Boca Raton, FL: CRC Press, 2011. 
References

[1] "Abnormal situation management - effective automation to improve operator performance", Honeywell Inc., Philadelphia, 2007.

[2] B. Shneiderman, et.al. Designing the user interface: strategies for effective human-computer interaction, Hoboken: Pearson, 2016.

[3] S. Serdiuk. Erhonomichni pytannia proektuvannia liudyno-mashynnykh system. Zaporizhzhia: ZNTU, 2014.

[4] B. Hollifield, et.al. The high performance HMI handbook, Kalamazoo: Digital Books, 2008.

[5] A. Anokhyn. "Problemy orhanyzatsyy cheloveko-mashynnoho ynterfeisa ASU TP AES", Doklady BHUYR, no. 2, vol. 88, 2015, pp. 104-108.

[6] A. Stopakevych, et.al. "Development of computer-integrated systems for the automation of technological process of associated gas processing", Eastern-European Journal of Enterprise Technologies, no. 3, pp. 4-12, 2017.

[7] A.F. Arabadzhy, et.al. "Syntez dvukhurovnevoi systemy upravlenyia rektyfykatsyonnoi kolonnoi v tekhnolohycheskom protsesse pererabotky poputnykh neftianykh hazov". Avtomatyzatsyia tekhnolohycheskykh y byznes-protsessov, vol. 9, no.2, pp. 11-17, 2017.

[8] M. Endsley. Designing for situation awareness: an approach for user-centered design. Boca Raton, FL: CRC Press, 2011.

УДК 681.518.3

\title{
СПЕКТРАЛЬНЫЕ ПЛОТНОСТИ РЕГУЛИРУЕМЫХ ПЕРЕМЕННЫХ ТИПОВЫХ САР И ИХ АППРОКСИМАЦИЯ МАЛОПАРАМЕТРОВЫМИ МОДЕЛЯМИ
}

\author{
В.А. Хобин ${ }^{1}$, С.И. Лагерная ${ }^{2}$ \\ 1,2Одесская национальная академия пищевых технологий, Украина \\ ORCID: ${ }^{1} 0000-0003-0238-8371 ;{ }^{2} 0000-0001-8138-3653$ \\ E-mail: silaodessa@gmail.com
}

Copyright $(2017$ by author and the journal "Automation technological and business - processes". This work is licensed under the Creative Commons Attribution International License (CC BY). http://creativecommons.org/licenses/by/4.0/

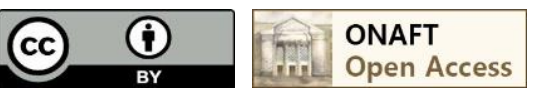

Анотация: В статье рассматриваются две группы математических моделей, которые описывают изменения регулируемых переменных замкнутых систем автоматического регулирования как случайных прочессов. Первая группа - содержательные модели, полученные на основе аналитических преобразований, которые отражают в модели спектральной плотности процесса все параметры моделей объекта, регулятора, возмущчений. Вторая группа - хорошо отражающие характер спектральной плотности, формальные модели, количество параметров которых минимально. Это позволяет вести их идентификаџию в реальном времени, в ходе штатного функционирования системы автоматического регулирования. Сравнение моделей, включая компьютерные эксперименты на основе имитационного моделирования, показывают потенциальную перспективность их применения для идентификации параметров моделей объектов регулирования в реальном времени и без размыкания контура регулирования систем автоматического регулирования.

Математическое описание системы автоматического регулирования в статье ведется, учитывая особенности объектов управления технологического типа - наличие запаздывания в каналах управления, подверженность неконтролируемым возмущениям (интенсивным координатным и параметрическим, низкочастотным).

Подробно рассмотрена прочедура получения математического выражения содержательных моделей 